\title{
Nurse intrauterine device training
}

\author{
Hilary Cooling, Wendy Dunster
}

\section{Background}

Nurses undertaking intrauterine device/intrauterine system (IUD/IUS) training have extra hoops to jump through. Trainer and trainee benefit from being aware of these and both can learn from the process. This article shares the personal experience of one trainer/trainee pair, both of whom enjoyed the experience and who wish to share the lessons learned with others.

\section{Trainee's view}

It started last year. My GP practice had one part-time IUD fitter and no one else wanted to train. So I said I would be interested if the courses were available for nurses to train. My nursing background consisted of 2 years of gynaecology, my midwifery training, family planning English National Board course, cervical cytology and a well woman diploma. The Margaret Pyke Trust offered a theory training day for applicants who fitted the Royal College of Nurses (RCN) criteria and who had a recognised practical trainer arranged.

The hunt was on. I was very lucky that the doctor trainer at our local contraception and sexual health (CASH) service said she would be happy to take on the training once the theory course was completed. I would be her first nurse trainee.

The Margaret Pyke Centre covered all the aspects of the theory required for IUD fitting including practical aids, though the travelling to London from Bristol was wearing.

The local CASH clinic was more accessible; however, I had to fit it in with my working day and times for their clinics. Not every session could guarantee an IUD fitting but this allowed me to watch Implanon ${ }^{\circledR}$ fitting and do routine contraception. The atmosphere was relaxed and friendly and I felt very comfortable learning to be a "quick fit fitter" (as one of our receptionists called me).

The biggest learning curve was the bimanual examinations and assessing the lie of the uterus: a new concept to a nurse. As a midwife I had assessed the gestation of women's pregnancies and dilation of the cervix during labour, but had never assessed a non-pregnant uterus. The IUD/IUS insertion kits were straightforward and, as is the case with anything new, practice with them made them more familiar.

The doctor trainer was brilliant, easy to work with, knowledgeable and made me feel extremely comfortable whilst I attended the clinics. Having to observe five insertions before doing any myself was, I felt, excessive. I would have preferred a practical session, as little can be observed when someone else is fitting an IUD. It took attendance at six sessions to accumulate my 10 required fittings to complete my training.

J Fam Plann Reprod Health Care 2008; 34(3): 193-194

Central Health Clinic, Contraceptive and Sexual Health Service, Bristol, UK

Hilary Cooling, FFSRH, Associate Specialist

Air Balloon Surgery, Bristol, UK

Wendy Dunster, RGN, Nurse Manager

Correspondence to: Dr Hilary Cooling, Central Health Clinic, Contraceptive and Sexual Health Service. Tower Hill, Bristol BS2 0JD, UK. E-mail: hilary.cooling@ubht.nhs.uk
Since then I have been very busy, and there I was worrying about obtaining the minimum of 12 IUD fittings per year to keep up my competencies! In recent months there has been a lot of press coverage about long-acting reversible contraception (LARC) and the need for the service to be more widely available. With contraception services stretched and unwanted pregnancy numbers rising together with abortion rates, LARC should be more readily available in general practice.

Training should be more widely available for those wishing to develop in these areas. Practice-based commissioning should allow us to use each other's services such as Implanon and IUD fitting to prevent unnecessary use of contraceptive services designed for the under-25s.

\section{Trainer's view}

This was the first time I had trained a nurse in intrauterine techniques. In preparation I had read the RCN training guidance for nurses and midwives, Fitting Intrauterine Devices, ${ }^{1}$ and had discussions with trainers who had some experience and with nurses who had been trained.

Wendy was very systematic, something which the RCN guidance requires and which is encouraged in nurse training generally. This meant that she had carefully learned bimanual pelvic assessment and was able to demonstrate this at an early stage. In contrast, doctors whose gynaecology experience is limited to a 6-month $\mathrm{SHO} / \mathrm{F} 2$ post frequently have a hazy grasp of the concept of uterine position and size, how to assess them and what the implications are for the next step of the IUD insertion process.

One incident left us both smiling. A patient had been referred to the specialist IUD clinic because the GP had difficulty locating the cervix. The conversation before seeing the patient went like this:

Hilary: I'll insert the speculum and then hand over to you for the next stage.

Wendy: Actually I'd like to do it - that's what happens in the GP practice when colleagues doing cervical smears can't find a cervix they ask me to help.

So she did, very competently. I reminded myself as an experienced trainer about learning from the training process, and about how to support an experienced learner in joining up their prior experience with what is new. On reflection perhaps I shouldn't have been surprised but I was.

Trainees do, of course, need to learn technical competence along with the necessary attitudes and communication skills. Through training in cervical cytology sampling Wendy had learned and developed an intuitive style in helping women who are understandably nervous about vaginal examination and IUD insertion. I told her I'd be pleased for doctor trainees to learn by observing her communication skills and ability to get on with the job (i.e. talking with the patient at the same time as fluently doing the procedure).

The RCN guidance is absurd in requiring the learner to observe the trainer doing five insertions in patients: one is usually sufficient, supplemented of course with extensive practice with models. And there should be explicit provision for some insertions to be supervised by trainers other than the primary trainer, to provide flexibility and to increase the validity of the assessment process. 
Doctors sometimes find nurses' practice protocoldriven, with the potential for rigidity. This is probably the flipside of being systematic, and doctors can also demonstrate it. I try to avoid this by encouraging a questioning approach that engages the learner cognitively in thinking not only about what to do but why. Wendy was also doing a nurse prescribing course and chose to focus on LARC methods for a presentation; this generated natural opportunities for discussion and helped towards a coherent approach to the whole topic.

\section{Concluding remarks}

This training situation provided learning opportunities for both the trainer and trainee. As trainer, the first author (HC) learned about making assumptions, and about encouraging doctors to emulate nurses' systematic approach. The next stage could be for nurses who are recognised trainers and experienced in IUD insertion to supervise the training of doctors. This will involve some changes in the Faculty of Sexual and Reproductive Healthcare (FSRH) rules, and maybe also some wider questioning of assumptions.

\section{Statements on funding and competing interests}

Funding Hilary Cooling's department has received support for educational meetings from all the major contraception suppliers and manufacturers.

Competing interests None identified.

\section{Author's note}

Hilary Cooling is a member of the FSRH Standing Committee on General Training. The opinions expressed in this article are her own and do not reflect FSRH policy.

\section{Reference}

1 Royal College of Nursing. Fitting Intrauterine Devices: RCN Training Guidance for Nurses and Midwives. October 2007. http://www.rcn.org.uk/_data/assets/pdf_file/0003/78762/0031 79.pdf [Accessed 2 February 2008].

\section{NEWS ROUNDUP}

\section{Safe, legal abortion for all}

The Council of Europe on 16 April 2008 called for women throughout its 47 member states to be guaranteed the right to "safe and legal" abortion. The Committee on Equal Opportunities for Women and Men considered that a ban on abortions does not result in fewer abortions, but mainly leads to clandestine abortions, which are more traumatic and more dangerous. Whilst most member states permit abortion where the life of the mother is at risk, there are several (including Andorra, Ireland, Malta, Monaco and Poland) where abortion is illegal or severely restricted. Despite objections from Poland and other nations and after a 4-hour debate, the member states of the Council of Europe voted to:

- Decriminalise abortion, if they have not already done so.

- Guarantee womens's effective exercise of their right to abortion and lift restrictions which hinder, de jure or de facto, access to safe abortion.

- Adopt appropriate sexual and reproductive health strategies, including access of women and men to contraception at a reasonable cost and of a suitable nature for them as well as compulsory relationships and sex education for young people.

\section{Source: http://assembly.coe,int/Main.asp?link=/Documents/}

WorkingDocs/Doc08/EDOC11537.htm

\section{Research evaluates the} effectiveness of UAE

Fibroids can cause heavy painful periods and impair both urinary and reproductive functions. The standard treatment is hysterectomy but new research published by the National Institute for Health Research Health Technology Assessment (NIHR HTA) programme suggests that uterine artery embolisation (UAE) may provide a useful alternative. UAE is less invasive than hysterectomy and offers women the possibility of retaining fertility by reducing the size of fibroids. The treatment also reduces hospital stay and recuperation time. Previous research has shown UAE to be effective over a 12-month period, however there is no evidence on its long-term effectiveness. Professor Klim McPherson at the University of Oxford recruited around 1700 women from 20 collaborating hospitals over 8 years to evaluate the safety, and the clinical and cost-effectiveness of UAE compared with hysterectomy. Patients were followed up using a questionnaire that looked at complication rates, patient satisfaction, fibroid shrinkage, aftercare treatment and the number of pregnancies following the treatment with UAE. The research team concluded that UAE is a safe and effective alternative for fibroids. They found that complications are less common for UAE than hysterectomy, particularly those that are deemed severe or major. From the economic analysis the researchers suggest that UAE would be a costeffective treatment for women who would like to retain fertility or to prevent early onset of menopause. ${ }^{1}$

\section{Reference}

1 Hirst A et al. Multi-centre retrospective cohort study comparing the efficacy, safety and cost-effectiveness of hysterectomy and uterine artery embolisation for the of hysterectomy and uterine artery embolisation for the treatment of symptomatic uterine fibroids. The $1-248$.

\section{Remote-controlled vasectomy}

A team from the University of Adelaide, Australia, may have come up with a more easily reversed alternative to vasectomy. They have designed a small radio-controlled valve that would "push-fit" snugly inside the vas deferens and block the passage of sperm. "It will be like turning a TV on and off with a remote control", said team founder, Derek Abbott, "except that the remote will probably be locked away in your local doctor's office to safeguard against accidental pregnancy or potential misuse of the device". Another advantage of the microvalve is that it would not require open surgery, unlike a vasectomy. The 800 micron long device could simply be inserted using a hypodermic needle. "The procedure could be performed in a special clinic rather than in a hospital", said Abbott.

\section{Reference}

Jones I et al. Wireless RF communication in biomedical applications. 2008 Smart Mater Struct 2008; 17: 015050 (10 pp). DOI: 10.1088/0964 $1726 / 17 / 1 / 015050$

\section{Gynaecological information on the Internet}

A free-to-use website, AskMyGyn.com, has been set up by a group of American gynaecologists. As well as information written by board-certified gynaecologists on hundreds of topics, personal questions can be submitted for answers directly from a physician. The doctors were surprised that in the first month $40 \%$ of hits they received originated from countries such as Saudi Arabia, Malaysia, Kuwait and Iran. The senior consultant, Dr Saul Weinreb, of AskMyGyn.com commented: "Of course I'm happy that we can provide people with reliable information, but I'm concerned that these women may not have access to real healthcare providers".
Global priorities for sexual health At the 9th Congress of the European Federation of Sexology held in Rome in April 2008, a presentation was made on the Global Priorities for Sexual Health. The World Association for Sexual Health has identified eight areas where actions are needed to advance the level of sexual health in the world, and impact the general wellbeing of the community and society at large. These include:

- Recognition and promotion of fulfilled sexual rights for all.

- Construction of a world with equity and equality between women and men.

- Eradication of sexual violence.

- Elimination of sexually transmitted diseases including AIDS.

- Adoption of scientifically based comprehensive sexuality education.

- Recognition of the centrality of sexual health in the reproductive health programmes.

- Identification, treatment and prevention of sexual concerns, dysfunctions and problems

- Recognition of the importance of sexual pleasure as a component of well-being.

Source: E Rubio-Aurioles (World Association for Sexual Health, Mexico) speaking at the 9th Congress of the European Federation of Sexology, Rome, Italy, 16 April 2008

\section{HPV immunisation programme implementation}

Following advice from the Joint Committee on Vaccination and Immunisation (JCVI), the independent expert body that provides advice on vaccines, the Scottish Government is implementing a routine human papillomavirus (HPV) immunisation programme starting in September 2008. The vaccine will be for girls aged around 12-13 years. This is estimated to involve around 30000 girls each year. In addition there will be a catch-up campaign for girls aged under 18 years at September 2008, when routine immunisation will start. The new immunisation programme is intended to protect girls in Scotland against developing cervical cancer. The Scottish Government is funding the cost of the vaccine and the communications campaign, which will be in the region of $£ 64$ million over 3 years. The UK Government is also committed to rolling out both routine and catch-up programmes for HPV.

Source: Public Health and Wellbeing Directorate, The Scottish Government. www.scotland.gov.uk

Reviewed by Henrietta Hughes, MRCGP, DFSRH General Practitioner, London, UK 